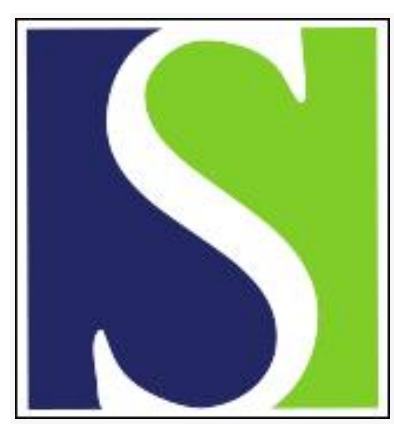

Scand J Work Environ Health 1982;8(1):24-28

https://doi.org/10.5271/sjweh.2500

Issue date: Mar 1982

A validation of questionnaire information on occupational exposure and smoking.

by Pershagen $\mathrm{G}$, Axelson $\mathrm{O}$

Key terms: arsenic; bias; lung cancer; lung cancer; occupational exposure; questionnaire; register; smelter work; smoking; validation

This article in PubMed: www.ncbi.nlm.nih.gov/pubmed/7134919

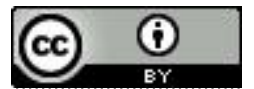




\title{
A validation of questionnaire information on occupational exposure and smoking
}

\author{
by Göran Pershagen, MD, ${ }^{1}$ Olav Axelson, MD, ${ }^{2}$
}

\begin{abstract}
PERSHAGEN G, AXELSON O. A validation of questionnaire information on occupational exposure and smoking. Scand $j$ work environ health 8 (1982) 24-28. Occupational exposure information obtained via a questionnaire to close relatives of 160 deceased smelter workers was compared with data from employee registers. The data from the questionnaire regarding employment at the smelter had a very high validity, ie, a sensitivity of $98 \%$ and a specificity of $99 \%$. When an assessment of arsenic exposure was made from information in the questionnaire, the sensitivity was only $40 \%$, but the specificity was over $90 \%$. Data on smoking habits were available from medical files for only 14 of the subjects. For all 14, the information was identical to the data in the questionnaires. It appears that questionnaires may sometimes be of use for exposure assessments in occupational health epidemiology.
\end{abstract}

Key terms: arsenic, bias, lung cancer, registers, smelter work.

Data on occupational exposure and important background variables like smoking are often difficult to obtain in retrospective epidemiologic studies of diseases with long latency, eg, cancer. In order to minimize the risk of observational bias, the information should, whenever possible, be gathered from sources containing data collected prior to the individual's disease or collected without knowledge of the disease. When such sources are not available, exposure in case-referent studies has sometimes been assessed from questionnaires or personal interviews with the study subjects or relatives (5). It has been suggested that this type of study is sensitive to various forms of observational bias, either due to difficulties in recall or to exaggeration by the interviewer.

An increased mortality from lung cancer has been observed in several occupational groups with exposure to inorganic

1 Department of Environmental Hygiene, Karolinska Institute and National (Swedish) Institute of Environmental Medicine, Stockholm, Sweden.

2 Department of Occupational Medicine, Universty Hospital, Linköping, Sweden.

Reprint requests to: Dr G Pershagen, National Institute of Environmental Medicine, Box 60 208, S-104 01 Stockholm, Sweden. arsenic compounds. Evidence has come from copper smelter workers $(7,15,17)$, pesticide production workers $(6,8,11)$, and vintners $(4,16)$. Two Swedish casereferent studies on workers from the same copper smelter have indicated a consistent excess mortality from lung cancer among workers with heavy arsenic exposure $(2,12)$. The exposure information was collected differently in the two studies, ie, via personal interviews, according to a questionnaire, with relatives of the subjects in one study and via employee records in the other. Although the base populations in the studies were not identical, the same individuals were included to a great extent in both studies. The purpose of this report was to evaluate the validity of the information on occupational exposure obtained from the questionnaire in comparison to the exposure classification derived from the employee records. Moreover, some aspects of the assessment of smoking habits are elucidated.

\section{Materials and methods}

Both studies were designed according to the case-control or case-referent technique as described by Miettinen (10). In the pres- 
ent report the study by Pershagen (12) will be referred to as study I and the study by Axelson et al (2) as study II. Full descriptions of the materials and methods are given in the original papers and will only be summarized in the present report.

\section{Source of subjects}

Study I. The cases and referents of study I were extracted from the National Register on Causes of Death, from subjects residing in two of the parishes (Bureå and St Örjan) surrounding the Rönnskärsverken copper smelter at the time of death. The register contains information from the death certificate, which has been shown to be of high validity for most diagnoses (3). As cases, served all men who had died between 1961 and 1974 from primary tumors of the trachea, bronchus, lung, pleura or mediastinum, ie, a total of 32 subjects. Four referents were selected for each case among those who had died from the remaining causes during this time period. The referents were matched with the cases according to year of birth.

Study II. The cases and referents of study II were gathered from the register of deaths and burials (containing information from the death certificate) in the parish of St Örjan. In all, 369 deaths were recorded for men aged $30-74 \mathrm{a}$ in $1960-1976$, including 27 cases of bronchial cancer. The referents were subjects who had died from the remaining causes, excluding malignant diseases other than bronchial cancer, cardiovascular disease, cerebrovascular disease, and cirrhosis of the liver (which were all suspected to be related to arsenic exposure) as well as, unclear diagnoses, mental deficiency, and diabetes mellitus. The remaining, "refined" referent group consisted of 79 subjects.

\section{Assessment of exposure}

Study I. A close relative (parent, wife or child) of each of the cases and referents of study I was interviewed by an officer from the local public health board according to a standardized questionnaire. The type of occupation, employer, and duration of every job during the life of the cases and referents were recorded, as well as smoking habits. All interviews were blind, ie, the interviewer had no knowledge of whether the subject of the interview belonged to the case or referent group. Smelter workers with more than $5 \mathrm{a}$ of employment as roasting furnace men, arsenic workers, or repair shop workers were regarded as heavily exposed to arsenic. Subjects who had never smoked daily were considered nonsmokers.

Study II. Employee registers had been kept since the start of operations at the smelter in 1928. The records contained detailed information on the time spent in various workplaces by each worker. In study II the arsenic exposure levels at the various workplaces was assessed by an experienced safety engineer, and workers were allocated into three different exposure categories depending on the time spent at different workplaces, the latency period for lung cancer also being taken into consideration. Information on smoking habits was obtained from medical records kept by the plant physician.

\section{Statistical methods}

The computation of estimated rate ratios in this paper were performed according to Mantel \& Haenszel (9), and approximate confidence limits were established as suggested by Miettinen (10). To obtain comparability between studies I and II, a recalculation was made of table 3 in study II using never employed as the reference category.

\section{Results}

In table 1 the information from the questionnaire is compared with data from employee registers for the whole group of cases and referents. The data from the questionnaire was taken as the operational measure, and the data from the employee registers as the "true" measure. A high validity of the information in the questionnaire on smelter work for the 160 subjects was evident, ie, a sensitivity of $98 \%$ and specificity of $99 \%$. The individual who was not reported as a smelter worker on the questionnaire had, according to the employee registers, been employed 2.5 
months at the smelter in the early 1930s.

Forty-seven of the total of 59 subjects employed at the smelter in study I were also included in study II. In this group the high arsenic exposure group in study I was compared with the two highest arsenic exposure categories in study II. In table 2 it is shown that the sensitivity was $46 \%$ (11 of 24$)$ when workers with high arsenic exposure were determined according to the information in the ques-

Table 1. Comparison of information on employ. ment at the smelter from a questionnaire and from occupational records.

\begin{tabular}{lccr}
\hline \multirow{2}{*}{$\begin{array}{l}\text { Question- } \\
\text { naire }\end{array}$} & \multicolumn{3}{c}{ Occupational records } \\
\cline { 2 - 4 } \cline { 2 - 4 } & $\begin{array}{c}\text { Smelter } \\
\text { work }+\end{array}$ & $\begin{array}{c}\text { Smelter } \\
\text { work }\end{array}$ & Total \\
\hline $\begin{array}{l}\text { Smelter } \\
\text { work }+\end{array}$ & 58 & 1 & 59 \\
$\begin{array}{l}\text { Smelter } \\
\text { work }-\end{array}$ & 1 & 100 & 101 \\
\hline Total & 59 & 101 & 160 \\
\hline
\end{tabular}

Sensitivity $=58 / 59=0.98$

Specificity $=100 / 101=0.99$

Table 2. Comparison of information on high arsenic (As) exposure from a questionnaire and from occupational records.

\begin{tabular}{lccc}
\hline & \multicolumn{3}{c}{ Occupational records } \\
\cline { 2 - 4 } $\begin{array}{l}\text { Question- } \\
\text { naire }\end{array}$ & $\begin{array}{c}\text { High As } \\
\text { exposure }+\end{array}$ & $\begin{array}{c}\text { High As } \\
\text { exposure }\end{array}$ & Total \\
\hline $\begin{array}{l}\text { High As } \\
\text { exposure }+\end{array}$ & 11 & 2 & 13 \\
$\begin{array}{l}\text { High As } \\
\text { exposure }\end{array}$ & 13 & 21 & 34 \\
\hline Total & 24 & 23 & 47 \\
\hline
\end{tabular}

Sensitivity $=11 / 24=0.46$

Specificity $=21 / 23=0.91$ tionnaire. The specificity was $91 \%$, ie, 21 out of 23 workers who were not included in the two highest exposure categories in study II were not considered to be heavily exposed to arsenic in study I.

The smoking habits had only been recorded by the plant physician for 14 of the 47 smelter workers included in both studies. In this group the data was identical to the information in the questionnaire (1 nonsmoker and 13 smokers).

In table 3 the Mantel-Haenszel rate ratios (RR) for high arsenic exposure and smelter work are given for studies I and II in relation to the subjects never employed at the smelter. The RR for high arsenic exposure was 7.3 in sudy $I$ and 10.1 in study II and for smelter work 2.6 and 3.4, respectively. The higher RRs in study II are partly explained by the exclusion of subjects with arsenic-related causes of death from the reference group (see the section Source of Subjects).

\section{Discussion}

The results of this comparative study show a high validity of information on occupation from relatives of the deceased. Careful consideration was given to the selection of subjects to be questioned, the standardization of the personal interviews, and blinded procedures. The information gathered on employment had the same quality as carefully kept occupational records. When the work history within the smelter was considered, the sensitivity in assessing the occupational exposure among employees with heavy arsenic exposure was rather low, but due to a high specificity $(>90 \%)$ the information was obviously appropriate for risk assessments (table 3).

Table 3. Estimated rate ratios for lung cancer with $95 \%$ confidence intervals for smelter workers including workers with high arsenic exposure (see text).

\begin{tabular}{|c|c|c|c|c|c|}
\hline & \multicolumn{2}{|c|}{ High arsenic exposure } & \multicolumn{2}{|c|}{ Smelter workers } & \multirow{2}{*}{$\begin{array}{l}\text { Not employed } \\
\text { at smelter } \\
\text { (Rate ratio) }\end{array}$} \\
\hline & Rate ratio & Confidence interval & Rate ratio & Confidence interval & \\
\hline Study I & 7.3 & $2.6-20.7$ & 2.6 & $1.2-5.9$ & 1.0 \\
\hline Study II & 10.1 & $3.4-30.0$ & 3.4 & $1.3-9.4$ & 1.0 \\
\hline
\end{tabular}

a Mantel-Haenszel rate ratios for lung cancer in relation to subjects never employed at the smelter. 
The interviews were carried out in 1977 , when some debate in the press had started about alleged cancer hazards of the smelter environment. The local union had been informed about lung cancer risks at some workplaces. In particular, arsenic had been pointed out as a possible causative agent. It is therefore likely that many of the relatives of the deceased smelter workers were aware of a possible relation between arsenic and lung cancer. However, this suspicion apparently had little effect on the validity of the occupational exposure information obtained through the interviews.

The workers at the Rönnskärsverken smelter have an increased mortality, not only from lung cancer, but also from circulatory diseases (2), and their average life span is shorter than that of the general population (18). In both our studies death was a prerequisite for the selection of referents, and consequently there might have been a slight tendency towards employment at the smelter being more common among the referents, which may lead to a somewhat conservative estimate of the risk ratio for lung cancer among the smelter workers. In the questionnaire study it was, however, considered important to have uniformity in the interview situation (all lung cancer cases were deceased) and a lack of knowledge for the interviewer on whether the subject was a case or referent in order to minimize the observational bias (1). In study II the tendency for a conservative estimate was counteracted by the utilization of a "refined" reference series, ie, the exclusion of individuals with diseases related to arsenic exposure from the reference group (table 3).

Information on smoking habits was obtained for all the subjects in the questionnaire study, and the comparison with data from the medical files of the plant physician indicated a high validity. At the same time it was obvious that the completeness of information on smoking in the medical files was insufficient, an experience which is commonly made in epidemiologic evaluations. The smoking habits among the smelter workers, as well as the interaction with occupational arsenic exposure, have been further elucidated in a separate study (14).
In summary, data on occupational exposure from the relatives of deceased persons have proved useful for exposure assessments. Employment records or other sources of occupational exposure information may not be available in retrospective epidemiologic studies on diseases with a long latency period. Furthermore, if the disease has a short clinical course and high fatality rate, eg, lung cancer, a direct interview with the subjects may not be possible. If used appropriately, standardized personal interviews with relatives of the deceased may constitute a valuable tool for obtaining exposure information in occupational health epidemiology.

Further studies comparing questionnaire information and employee registers are desirable in view of the generally held opinion that the validity of case-referent studies is questionable due to recall and/or interviewer bias.

\section{References}

1. Axelson O. A note on observational bias in case-referent studies in occupational health epidemiology. Scand $j$ work environ health 6 (1980) $80-82$.

2. Axelson $O$, Dahlgren $E$, Jansson $C-D$, Rehnlund SO. Arsenic exposure and mortality: A case-referent study from a Swedish copper smelter. $\mathrm{Br} \mathrm{j}$ ind med 35 (1978) 8-15.

3. de Faire U, Friberg L, Lorich U, Lundman $T$. A validation of cause-of-death certification in 1156 deaths. Acta med scand 200 (1976) 223-228.

4. Galy $P$, Touraine $R$, Brune J, Roudier $P$, Gallois P. Le cancer pulmonaire d'origine arsénical des vignerons du Beaujolais. J fr med chir thorac 17 (1963) 303-311.

5. Hardell L. Epidemiological studies on softtissue sarcoma and malignant lymphoma and their relation to phenoxy acid or chlorophenol exposure. Umeå University, Umeå 1981. (Umeå university medical dissertations, new series no 65: 1-139).

6. Hill AB, Faning EL. Studies on the incidence of cancer in a factory handling inorganic compounds of arsenic: I. Mortality experience in the factory. $\mathrm{Br} \mathrm{j}$ ind med 5 (1948) $1-6$.

7. Lee A, Fraumeni JF Jr. Arsenic and respiratory cancer in man: An occupational study. J natl cancer inst 42 (1969) 10451052.

8. Mabuchi K, Lilienfeld AM, Snell LM. Lung cancer among pesticide workers exposed to inorganic arsenicals. Arch environ health 34 (1979) $312-319$.

9. Mantel N, Haenszel W. Statistical aspects of the analysis of data from retrospective 
studies of disease. $\mathrm{J}$ natl cancer inst 32 (1959) $719-748$.

10. Miettinen OS. Estimability and estimation in case-referent studies. Am $\mathrm{j}$ epidemiol 103 (1976) 226-235.

11. Ott MG, Holder BB, Gordon HL. Respiratory cancer and occupational exposure to arsenicals. Arch environ health 29 (1979) $250-255$.

12. Pershagen G. Lung cancer mortality, occupational exposure and smoking habits in a region surrounding a smeltery. In: International symposium on the control of air pollution in the working environment, Stockholm 6-8 September 1977. International Labour Office, Geneva 1978, pp $179-185$.

13. Pershagen G, Elinder C-G, Bolander A-M. Mortality in a region surrounding an arsenic emitting plant. Environ health perspect 19 (1977) 133-137.

14. Pershagen G, Wall S, Taube A, Linnman L. On the interaction between occupational arsenic exposure and smoking and its relationship to lung cancer. Scand $j$ work environ health 7 (1981) $302-309$.

15. Pinto SS, Enterline PE, Henderson V, Varner MO. Mortality experience in relation to a measured arsenic trioxide exposure. Environ health perspect 19 (1977) 127-130.

16. Roth F. Über den Bronchialkrebs arsengeschädigter Winzer. Virchows Arch 331 (1958) 119-137.

17. Tokudome S, Kuratsune M. A cohort study on mortality from cancer and other causes among workers at a metal refinery. Int $j$ cancer 17 (1976) 310-317.

18. Wall S. Survival and mortality pattern among Swedish smelter workers. Int $j$ epidemiol 9 (1980) $73-87$.

Received for publication: 15 October 1981 